A N N A L E S Annales de Bretagne et des Pays de l'Ouest

\title{
La navigation intérieure sous l'Ancien Régime
}

\section{Pierrick Pourchasse}

\section{OpenEdition}

\section{Journals}

Édition électronique

URL : http://journals.openedition.org/abpo/3234

DOI : $10.4000 / a b p o .3234$

ISBN : 978-2-7535-5040-7

ISSN : 2108-6443

\section{Éditeur}

Presses universitaires de Rennes

Édition imprimée

Date de publication : 22 avril 2016

Pagination : 209-210

ISBN : 978-2-7535-5038-4

ISSN : 0399-0826

\section{Référence électronique}

Pierrick Pourchasse, "La navigation intérieure sous l'Ancien Régime », Annales de Bretagne et des Pays de I'Ouest [En ligne], 123-1 | 2016, mis en ligne le 22 avril 2016, consulté le 23 septembre 2020. URL http://journals.openedition.org/abpo/3234 ; DOI : https://doi.org/10.4000/abpo.3234 
notamment en supportant une fiscalité pesante, mais dont les élites tirent pour elles-mêmes avantage de cette obéissance.

L'historien trouvera dans les quatre volumes que le travail érudit de Robert Favreau met à sa disposition, une riche matière documentaire à l'appui de la thèse de celui-ci (FAVREAU, Robert. La ville de Poitiers à la fin du Moyen Âge. Une capitale régionale. Poitiers, Société des Antiquaires de l'Ouest, 1978. 2 vol). Le simple curieux, que la lecture d'un texte en ancien français et la rédaction parfois technique et aride d'articles consignant des décisions administratives pourraient désorienter, préférera une entrée par l'index des noms de lieux. La rubrique " Poitiers ", déclinée en un grand nombre de thèmes, ouvre de multiples fenêtres sur la vie quotidienne $\mathrm{au} \mathrm{XV}$ siècle, et invite à la flânerie dans la vieille ville actuelle pour y retrouver le souvenir des rues et des édifices, en marchant sur les pas des puissants comme des humbles dont les registres des délibérations du corps de ville ont gardé les noms, les faisant par la même occasion entrer dans l'histoire.

Michel BOCHACA

SzULman, Éric, La navigation intérieure sous l'Ancien Régime, Rennes, PUR, coll. " Histoire" " 2014, 378 p.

L'ouvrage d'Éric Szulman présente un sujet original : la politique des autorités françaises concernant les voies navigables entre 1660 et 1792. L'auteur interroge sur la longue durée les modalités de l'intervention publique dans la conception d'un réseau de circulation fluviale à l'échelle nationale. La volonté d'améliorer les voies d'eau du royaume devient une préoccupation publique au temps de Colbert; les règles portant sur la navigation sont intégrées à la réformation des eaux et forêts de 1669. Le propre d'un cours d'eau est d'être chose publique et la police des rivières est définitivement organisée. Cependant, à la fin du XVII siècle, si les autorités manifestent un intérêt certain pour le transport par voie d'eau, la perception des améliorations envisageables et le manque de centralisation administrative empêchent la rationalisation de l'ensemble des projets autour d'un dessein global. La grande décision du règne de Louis XIV est la construction du canal du Midi qui n'obéit pas à des motifs économiques, comme on le pense généralement, mais à une logique militaire et stratégique. Les contraintes financières de la monarchie conduisent à la pratique des concessions mais ce système aboutit à des blocages dus aux rivalités entre grands nobles concessionnaires et à un gel partiel des constructions pendant plusieurs décennies.

L'administration des Ponts et Chaussées relance l'intérêt pour les voies navigables à partir des années 1740. Le système des concessions qui se traduit par la patrimonialisation des canaux, usage néfaste au développement économique, est très critiqué. Pour les spécialistes comme ceux de l'Académie des sciences, l'État et les pouvoirs locaux doivent désormais prendre en charge ces investissements productifs qui seront bénéfiques en améliorant les rentrées fiscales. Si les concessions perdurent, Trudaine, intendant des finances et directeur du commerce, s'entoure d'experts et limite l'attribution de nouveaux privilèges qu'il encadre rigoureusement. En juillet 1764, sous l'action de Bertin, " la Navigation dans l'intérieur du royaume " s'émancipe des Ponts et Chaussées et devient une administration à part entière. C'est une véritable rupture visant à rendre entièrement publics la gestion, la construction et l'entretien des voies d'eau. Bertin établit un plan de navigation fluviale pour mettre un terme aux déséquilibres spatiaux, sociaux et économiques 
préjudiciables à l'ensemble du royaume. Une circulation gratuite sur les voies d'eau entre les différentes provinces assurerait un rééquilibrage des disparités de production, ferait baisser le prix des grains et mettrait fin aux disettes. De plus, le développement des voies d'eau et celui des chemins de terre doivent être indissociables et complémentaires. Enfin les concessions, coûteuses et inefficaces, sont à prohiber et à remplacer par des modes publics d'action. Le plan est ambitieux mais sans argent, sans véritable contrôle administratif de l'ensemble géographique concerné et confronté à de multiples oppositions, il doit finalement être abandonné. Cependant, la dynamique initiée constitue une étape essentielle à la construction d'un champ administratif dédié à la navigation intérieure.

Lors de son arrivée aux affaires, Turgot cherche, avec l'aide de savants comme Condorcet, à concrétiser le plan Bertin par des mesures financières et normatives. Le développement du réseau de voies navigables est un moyen pour stimuler les activités économiques et équilibrer le territoire national. En outre, la voie d'eau doit drainer les productions de l'intérieur vers les ports et les marchés extérieurs. Le financement des nouvelles constructions devient public et repose sur une imposition générale. Les pays d'États ne sont pas exemptés à l'exemple de la Bretagne qui doit payer 150000 livres pour les travaux à l'embouchure de la Loire dont le coût total monte à 250000 livres. L'administration des Ponts et Chaussées prend à nouveau le contrôle de la gestion des voies d'eau et donne l'impulsion à de nouvelles constructions. Si l'expérience ne dure guère, elle se traduit par une montée en puissance de l'intérêt public pour la navigation intérieure.

Entre 1760 et 1790, la France est agitée par " une fièvre hydraulique ». La "publicisation " (c'est-à-dire la présentation des propositions au public) est un moyen de pression sur l'administration, en témoigne l'action du marquis de Brie-Serrant qui promeut un projet mixte de port et de canal artificiel entre Nantes et la mer. L'administration se transforme, le département en charge de la navigation intérieure se structurant pour s'adapter aux nouvelles exigences politiques. De leur côté, les administrations provinciales définissent leur choix dans le cadre et au nom de la politique menée au niveau national. Ainsi, le comte de Piré, très actif dans le domaine de la navigation fluviale, place les projets bretons dans la perspective d'un réseau national. La commission intermédiaire de la navigation intérieure de Bretagne a pour projet de relier la Rance, la Vilaine et la Mayenne " par deux canaux navigables qui conduiront à Saint-Malo et à Nantes ". Cependant, l'instabilité ministérielle engendre des politiques discordantes notamment en matière de financement. Le problème est naturellement la mobilisation des fonds (impositions diverses, emprunts, crédit privé...). Ainsi, les États de Bretagne acceptent de financer par un emprunt le plan régional de navigation intérieure du comte de Piré. La conduite des travaux est tout aussi désorganisée et sujette aux malversations. Malgré six ans et deux millions de livres de travaux, la navigation entre Rennes et Redon n'est toujours pas possible en 1790. Parallèlement à l'effort de construction, le Contrôle général organise une réforme des méthodes d'entretien des voies navigables. Cependant, cet élan amorcé par Bertin pour doter la France d'un réseau de navigation fluviale s'interrompt brutalement à la Révolution en raison de la politisation des débats et de la désorganisation financière et économique du royaume.

L'ouvrage d'Éric Szulman, bien écrit et d'une lecture facile, est un travail essentiel pour la connaissance à la fois de la perception économique de la navigation intérieure, des problèmes de financement et du fonctionnement administratif sous l'Ancien Régime où rivalités, conflits d'intérêts et luttes entre les différents pouvoirs sont la règle. 